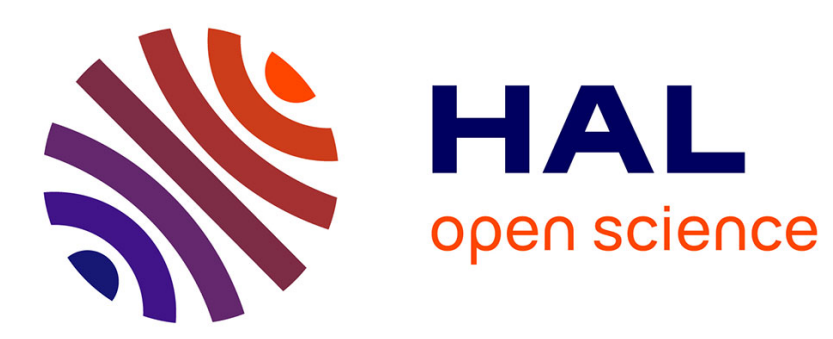

\title{
Remote sensing of soil surface characteristics from a multiscale classification approach
}

Christina Corbane, Damien D. Raclot, Frédéric Jacob, Jean Albergel, Patrick Andrieux

\section{To cite this version:}

Christina Corbane, Damien D. Raclot, Frédéric Jacob, Jean Albergel, Patrick Andrieux. Remote sensing of soil surface characteristics from a multiscale classification approach. CATENA, 2008, 75 (3), pp.308-318. 10.1016/j.catena.2008.07.009 . hal-02658154

\section{HAL Id: hal-02658154 https://hal.inrae.fr/hal-02658154}

Submitted on 3 Jun 2021

HAL is a multi-disciplinary open access archive for the deposit and dissemination of scientific research documents, whether they are published or not. The documents may come from teaching and research institutions in France or abroad, or from public or private research centers.
L'archive ouverte pluridisciplinaire HAL, est destinée au dépôt et à la diffusion de documents scientifiques de niveau recherche, publiés ou non, émanant des établissements d'enseignement et de recherche français ou étrangers, des laboratoires publics ou privés. 


\title{
Remote sensing of soil surface characteristics from a multiscale classification approach
}

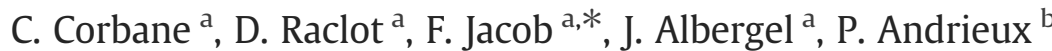 \\ a IRD, UMR LISAH INRA-IRD-SupAgro, 2 place Viala, 34060 Montpellier, France \\ b INRA, UMR LISAH INRA-IRD-SupAgro, 2 place Viala, 34060 Montpellier, France
}

\begin{abstract}
Due to their significant influence on infiltration/runoff partitioning and soil erosion, hydrological soil surface characteristics (SSC) have to be known in a spatially distributed manner. This paper proposes a new approach based on radiometric and spatial remotely sensed information, for the mapping of hydrological SSC classes according to a predefined typology based on infiltration rates. Traditional remote sensing approaches usually focus on single SSC attributes only, where the latter correspond to key structural properties such as micro topography, surface crusting and soil cover. The originality of the method proposed here is considering the composite nature of SSC classes, by combining the aforementioned single attributes. This method makes use of a multiscale image segmentation that allows extracting image objects at two spatial scales of interest. At the fine scale, each Homogeneous Unit (HU) is assigned to an SSC attribute. At the coarse scale, SSC classes are identified by combining $\mathrm{HU}$ of SSC attributes assigned at the fine scale. The method was applied on airborne images collected over a Mediterranean vineyard by a small Pixy drone, and validated using intensive ground-based observations. The results showed acceptable performances with an overall accuracy ranging from 63 to 84\%, depending on SSC classes and surface conditions. However, unsystematic confusions still remained between SSC classes which significantly differ in terms of hydrological behaviours. Improvements are expected considering richer spectral information, and ancillary information about SSC evolution in the case of intensive temporal monitoring.
\end{abstract}

\section{Introduction}

Due to their significant influence on land surface hydrological processes such as infiltration/runoff partitioning and soil erosion, soil surface characteristics (SSC) constitute an essential information for hydrological modelling (Auzet and Boiffin, 1995; Jetten et al., 1996; Le Bissonnais et al., 1998; Cerdan et al., 2001; Moussa et al., 2002). Various attempts have been made to define SSC through a comprehensive and consistent set of structural properties, by often referring to the spatial organization of different structural properties. The most commonly cited structural properties are vegetation type and density (Snelder and Bryan, 1995; Robinson and Phillips, 2001), soil roughness and stoniness (Poesen and Lavee, 1994; Govers et al., 2000), and terrain slope (Janeau et al., 2003). Casenave and Valentin (1992) also defined visual indicators for the surface crust morphology over Sahelian regions. Finer properties are sometimes considered, such as the macro porosity that results from biological activity (Dunne et al., 1991). Although they have been widely used in several studies, the concepts of SSC and related spatial extent still remain poorly defined.

\footnotetext{
* Corresponding author. Tel.: +33 49961 2809; fax: +33 467632614

E-mail address: frederic.jacob@supagro.inra.fr (F. Jacob).
}

A hydrologically based typology that relies on infiltration rate was proposed by Andrieux et al. (2001) for cultivated areas under Mediterranean conditions. It consists of combining structural properties, here designated as attributes, associated with micro topography (i.e. soil roughness which depends on soil treatment), surface crusting, and soil cover (i.e. density of grass or organic litter).

Due to strong spatial variabilities for most of attributes, field surveys of SSC are labour intensive and costly. A promising alternative is using remote sensing for capturing spatial information, as successfully done for the retrieval of surface roughness (Baghdadi et al., 2002), humidity (Wang et al., 1997) and soil organic matter (Wiegand et al., 1992), especially under specific conditions such as bare soil or sparse vegetation. Similarly, relations between reflectance and infiltration rates (Goldshleger et al., 2001, 2002) or surface crusting (Goldshleger et al., 2002; Ben-Dor et al., 2003, 2004; Goldshleger et al., 2004) were highlighted over bare soils, by following works from De Jong (1992) and Metternicht and Fermont (1998) about the potential of spectral information over the solar domain. Nevertheless, these studies usually focused on single attributes whereas infiltration/runoff partitioning is conditioned by a combination of several attributes (Descroix et al., 2001, 2002). Very few remote sensing studies considered hydrological SSC classes as combinations 
of attributes. Among them, Wassenaar et al. (2005) investigated the potential of multiangular information at very high spatial resolution over Mediterranean vineyards. For each SSC class from the typology of Andrieux et al. (2001), Bidirectional Reflectance Distribution Function (BRDF) within green and red wavebands was first characterized from ground-based goniometric measurements. SSC classes were next mapped from aerial photographs, by minimizing airborne radiometric measurements against BRDF-based predictions for specific illumination and viewing conditions. It was thus shown several SSC classes could be distinguished (e.g. crusted mineral soil surfaces or surfaces covered with litter and/or weed by more than half), although some of them remained difficult to discriminate because of strong dependence of predictions on illumination and viewing conditions.

SSC classes may also be distinguished from remote sensing by exploring the radiometric and spatial dimensions of the collected information. The latter have been utilized for inferring land cover (Phua et al., 2007), classifying wetlands or vegetation (Harken and Sugumaran, 2005; Yu et al., 2006), and mapping habitat or forest (Bock et al., 2005; Van Coillie et al., 2007). For these purposes, radiometric and spatial dimensions are jointly used through multiscale classifications. The latter rely on object-oriented frameworks and image segmentations, and allow extracting objects of interest by simultaneously segmenting at various scales. These scales are preselected using the scale factor that corresponds to a threshold of heterogeneity criterion between image objects. A multiscale classification results in a hierarchical network of image objects, each of them being related to i) neighbouring objects at the same scale, ii) sub objects at the finer scales and iii) super objects at the coarser scales (Baatz and Schape, 2000). Rather than dealing with spectral behaviours of individual pixels only, a multiscale classification therefore incorporates radiometric features and spatial arrangements such as texture, context, shape and relationships between objects (Laliberte et al., 2004).

In the context of mapping hydrological SSC classes from remote sensing, it is of interest to assess the potentialities of multiscale classification which uses radiometric and spatial remotely sensed information. Although such approach has been successfully applied for specific environmental issues as previously mentioned, its relevance for the characterization of hydrological SSC classes has to be proven. Expected difficulties are related to the composite nature of such SSC classes as compared to single attributes for Homogeneous Units (HU), including the selection of both segmentation levels and associated scale factors. Assuming patches of single SSC attributes are more easily extractable from remote sensing than patches of composite SSC classes (Corbane, 2006), a potential solution is segmenting images at two hierarchical spatial scales. First, HU of SSC attributes are detected at the fine scale. Next, SSC classes are characterized at the coarse scale using the fine scale classification of SSC attributes along with the hierarchical network between the objects at the two scales.

The current study aimed at assessing the potentialities of a two scale classification which uses radiometric and spatial remotely sensed information, for the mapping of SSC classes. The proposed approach was implemented over a dataset of digital airborne images collected by a Pixy@ drone within a Mediterranean vineyard environment. This enabled a comparison against the BRDF-based classification proposed by Wassenaar et al. (2005), while intensive ground-based observations allowed performing validation. The paper is structured as follows. We focus in Section 2 on the basic concepts about typology of hydrological SSC. We describe in Section 3 the study area and the data set that includes groundbased measurements and remotely sensed data. Section 4 describes the proposed two scale classification, as well as its implementation over the collected database. The results are next presented in Section 5, and discussed in Section 6. Wider issues and conclusions are reported in Section 7.

\section{SSC hydrological typology based on infiltration rates}

Among the various definitions suggested in the literature for characterizing SSC (see Introduction), we focused in the current study on the hydrologically based typology proposed by Andrieux et al. (2001). It was devoted to Mediterranean vineyards, and established according to infiltration rates. Measurements were collected during several experiments over various types of soil: calcaric regosol, chromic luvisol, calcaric cambisol, gleyic cambisol. The selected plots yielded a large variability of characteristics in terms of slope, grass cover, roughness, soil type, clay percentage, surface stone content, surface structure and initial soil moisture content (Leonard and Andrieux, 1998; Andrieux et al., 2001).

Measurements of infiltration rate were made in the field using a rainfall simulator as described by Asseline and Valentin (1978), with a rainfall intensity of $35 \mathrm{~mm} / \mathrm{h}$. Steady state infiltration rates were measured within $1 \mathrm{~m}^{2}$ size plots, since this spatial extent allowed minimizing edge effects and keeping the surface crust unchanged. A $10 \mathrm{~m}^{2}$ size peripheral buffer zone was watered to ensure vertical infiltration flow over the $1 \mathrm{~m}^{2}$ plot. This experimental setup allowed simulating rainfall with intensities close to those of natural conditions, such as the pressure head at the soil surface was realistic.

From these measurements, SSC were classified into several categories according to different soil infiltration rates (Leonard and Andrieux, 1998; Andrieux et al., 2001). When selecting the key SCC attributes for classification, those to be considered because of their significant influence on infiltration/runoff partitioning were soil micro topography, surface crusting, soil cover and stoniness. Soil micro topography of tilled surfaces was determined by considering four classes of soil clod size: i) lower than $1 \mathrm{~cm}$, ii) from 1 to $5 \mathrm{~cm}$, iii) from 5 to $10 \mathrm{~cm}$, and larger than $10 \mathrm{~cm}$. Were also distinguished i) clods of recently tilled soils that could be clearly individualized, ii) clods with a slightly formed thin structural crust and iii) tilled soil surfaces slightly sealed by raindrop impacts. The identification of the other SSC attributes is described in Corbane et al. (2008). Initial soil moisture and clay content were not considered, since Leonard and Andrieux (1998) demonstrated they had no significant influence on infiltration steady state rate, with a coefficient of determination lower than $0.1 \%$ and a significance level larger than $60 \%$.

On the basis of the selected attributes, the in situ identification of SSC classes was performed using a two step procedure. First, Homogeneous Units (HU), which included single attributes, were identified by following the instances reported in Table 1. Second, composite SSC classes, which contained several HU of different SSC attributes, were assigned to a given area according to the association rules presented in Table 2. For example, if more than half of surface was covered by a HU of "organic litter" and the remaining part was predominantly occupied by a HU of "surface crust", then the resulting SSC class was labelled "LC", which corresponded to an infiltration rate of about $18 \mathrm{~mm} / \mathrm{h}$. According to the experimental context of the current study (see Section 3), stoniness attribute and resulting SSC classes were not considered. This yielded considering six SSC classes, displayed in Table 2 with their infiltration rates as measured by Andrieux et al. (2001). In the context of SSC mapping for hydrological modelling, these classes were gathered into three groups according to

Table 1

Structural properties and their associated instances that strongly influence infiltration properties at the soil surface

\begin{tabular}{ll}
\hline $\begin{array}{l}\text { Structural properties } \\
\text { (SSC attributes) }\end{array}$ & Instances \\
\hline Soil micro topography & $\begin{array}{l}\text { Flat surface (untilled)/small clods with a slightly sealed } \\
\text { surface (previously tilled)/large clods (recently tilled) } \\
\text { None/structural crust/sedimentary crust } \\
\text { Nurface crusting }\end{array}$ \\
$\begin{array}{ll}\text { Soil cover } & \text { grass/litter }\end{array}$ \\
\hline
\end{tabular}


Table 2

The six SSC classes existing within the considered study area

\begin{tabular}{|c|c|c|c|c|}
\hline & Label & Definition & $\begin{array}{l}\text { Mean steady } \\
\text { infiltration rates } \\
(\mathrm{mm} / \mathrm{h})\end{array}$ & \\
\hline \multirow[t]{6}{*}{$\begin{array}{l}\text { SSC } \\
\text { classes }\end{array}$} & $\mathrm{T}$ & $\begin{array}{l}\text { The surface is mainly composed of } \\
\text { HU of } 5-10 \mathrm{~cm} \text { size clods }\end{array}$ & $31(\mathrm{SD}=4.3 ; N=5)$ & High \\
\hline & TC & $\begin{array}{l}\text { More than } 50 \% \text { of the surface is } \\
\text { composed of HU of clods with a } \\
\text { slightly sealed surface }\end{array}$ & $21(\mathrm{SD}=6.5 ; N=7)$ & Medium \\
\hline & GC & $\begin{array}{l}\text { More than } 50 \% \text { of the surface is } \\
\text { composed of HU of grass AND the } \\
\text { rest is predominantly composed of } \\
\text { HU of structural crust }\end{array}$ & $20.3(\mathrm{SD}=10.8 ; N=9)$ & \\
\hline & LC & $\begin{array}{l}\text { More than } 50 \% \text { of the surface is } \\
\text { composed of HU of litter AND the } \\
\text { rest is predominantly composed of } \\
\text { HU of structural crust }\end{array}$ & $18.2(\mathrm{SD}=6.3 ; N=20)$ & \\
\hline & STC & $\begin{array}{l}\text { More than } 50 \% \text { of the surface is } \\
\text { composed of HU of structural crust }\end{array}$ & $10.8(\mathrm{SD}=3.4 ; N=8)$ & Low \\
\hline & SDC & $\begin{array}{l}\text { More than } 50 \% \text { of the surface is } \\
\text { composed of } \mathrm{HU} \text { of sedimentary } \\
\text { crust }\end{array}$ & $7.6(\mathrm{SD}=2.6 ; N=19)$ & \\
\hline
\end{tabular}

Each SSC class is defined through its constituting HU of SSC attributes. The associated infiltration rates measured in situ with a $35 \mathrm{~mm} / \mathrm{h}$ rainfall intensity by rainfall simulator (Andrieux et al., 2001) are indicated. The six SSC classes are next assembled into the three groups for high, medium and low infiltration rates. The level of typology refinement depends on accuracy requirements for hydrological models. SD stands for standard deviation and $N$ for measurement number.

infiltration rates, and corresponded to different surface evolution stages. Thus, tillage results in T class (recently tilled), which naturally changes into TC class (priorly tilled and slightly sealed), then into STC class (structural crust), and finally into SDC class (sedimentary crust). Additionally, vegetation components are considered through GC (grass cover) and LC (litter cover) classes.
When dealing with in situ characterization of SSC classes, it is worth noting that the main difficulty is related to the lack of a clear definition for the corresponding spatial extent. This induces a strong subjectivity when determining the integration area for a given SSC class. This difficulty is usually overcome by considering the integration area as circumscribed within the considered agricultural field. However, within Mediterranean vineyards, SSC classes exhibit a strong subfield variability that cannot be easily mapped (Wassenaar et al., 2005; Corbane et al., 2008). Therefore, producing fine SSC maps is almost impossible. A potential solution is that proposed by the current study, i.e. exploiting radiometric and spatial remotely sensed information collected from very high spatial resolution sensor, along with an object-oriented two scale classification based on using HU of SSC attributes for the retrieval of SSC classes.

\section{Materials}

\subsection{Experimental area}

The experiment was carried out in Puisserguier $\left(43^{\circ} 22^{\prime} \mathrm{N}-3^{\circ} 2^{\prime} \mathrm{E}\right)$ on a vineyard site located in Languedoc-Roussillon, a Southern France region of wine production. The climate is sub humid Mediterranean, with a long dry season. Annual rainfall has a bimodal distribution with maxima in spring and autumn. The average annual rainfall over the last 20 years is approximately $650 \mathrm{~mm}$. High intensity storms are common in summer. The soil is fairly homogeneous with a sandy loam texture and a dominant brownish yellow color overlaying sandy clayey molasses.

This experimental site was selected because it concentrated the main soil management practices for Mediterranean vineyards. During the experiment, the cropping system included bilateral wire trained Syrah vine stocks covering an area of $8000 \mathrm{~m}^{2}$. Spacing between and along rows were respectively 2.5 and $1.0 \mathrm{~m}$. The agricultural practices implemented in 2000 included four types of soil management (see Fig. 1 for detailed

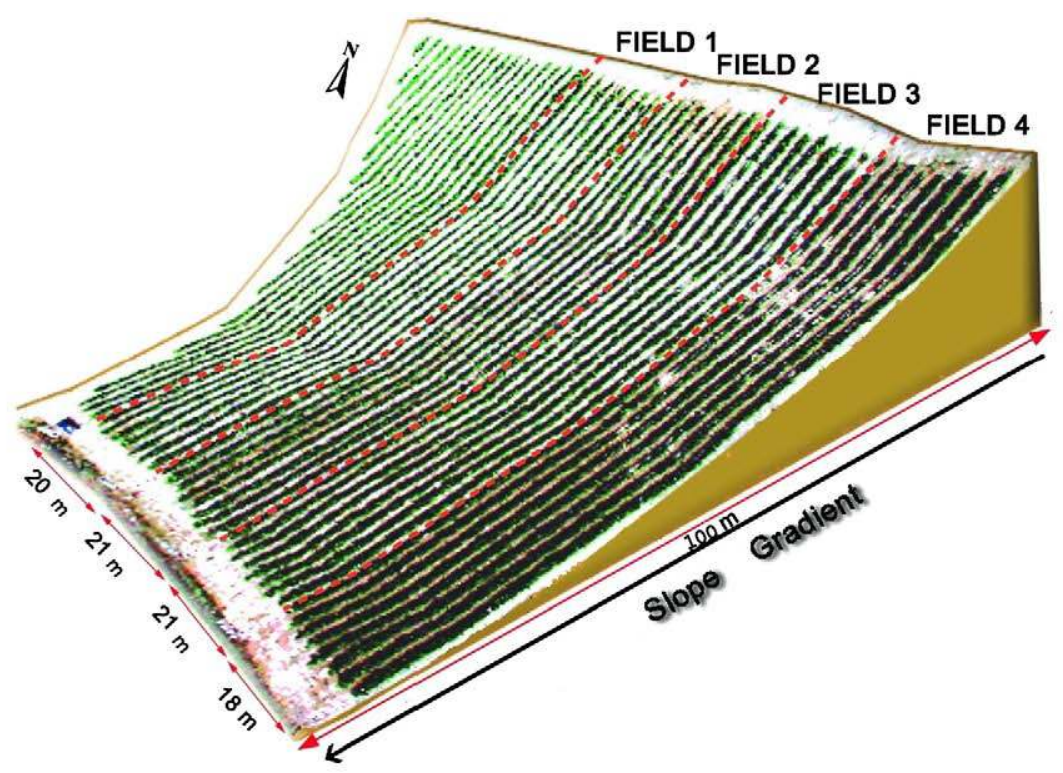

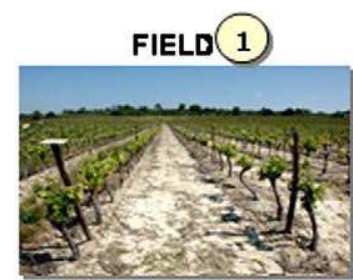

Bare soil controlled by chemical weeding

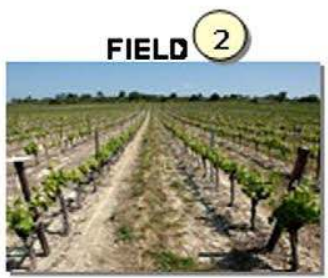

Natural grassing controlled by chemical weeding

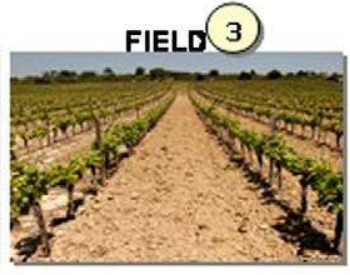

Natural grassing controlled by mechanical weeding

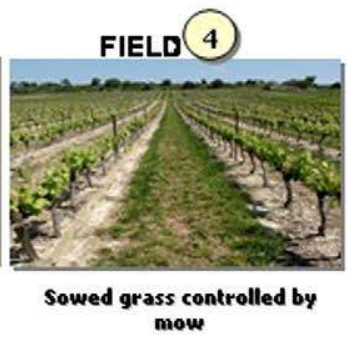

mow

Fig. 1. The experimental vineyard site. This site is divided into four fields, each subject to a specific soil management practice. 
dimensions of each field): bare soil controlled by chemical weeding (Field $1,2000 \mathrm{~m}^{2}$ ), natural grassing controlled by chemical weeding (Field 2, $2100 \mathrm{~m}^{2}$ ), natural grassing controlled by mechanical weeding (Field 3 , $2100 \mathrm{~m}^{2}$ ), and sowed grass controlled by mow (Field 4, $1800 \mathrm{~m}^{2}$ ). Ground-based and remote sensing measurements were collected during 4 days in 2004 (March 27, May 18, June 15 and July 23) that corresponded to dry soil conditions. An Enhanced Observing Period (EOP) for groundbased data was setup during one additional day in May 2004, in order to analyse the spatial variability of SSC attributes. Data collection and EOP are presented hereafter.

\subsection{Remote sensing data}

Following the works of Wassenaar et al. (2005), the use of Very High spatial Resolution (VHR) imagery was explored for its abilities to capture the soil surface fraction between the vine rows. The spectral range was selected according to literature materials. Several studies previously demonstrated the potential of surface reflectance over the solar spectral domain $(0.3$ to $3 \mu \mathrm{m})$, for consistently distinguishing different soil management practices such as tillage, non-tillage and mow (De Jong, 1992; Clegg et al., 1999). When focusing on the visible spectrum $(0.4$ to $0.7 \mu \mathrm{m})$, Lee et al. (1988) and Ben-Dor et al. (1999) reported soil reflectance significantly contributed to classification accuracy, and could therefore be used for soil interpretation. This spectrum was also successfully used for differencing crusted and non-crusted soils through color, where the latter was expressed as a cumulative product of reflectance between 0.4 and $0.7 \mu \mathrm{m}$ (Ben-Dor et al., 2003; Goldshleger et al., 2004). When studying crusting processes, a quantitative relationship between the latter and spectral parameters was observed from reflectance changes induced by laboratory treatments (Ben-Dor et al., 2004). Finally, although soil reflectance over the whole solar spectrum would have provided more information (Eshel et al., 2004), most of the attributes we considered here were previously better distinguished by their brightnesses rather than their reflectance spectra (Escadafal and Bacha, 1996; Lambin, 1999; Wassenaar, 2001). Regarding these elements, we expected reflectance data over the [0.4-0.7] $\mu \mathrm{m}$ spectrum would be relevant for the mapping of hydrological SSC classes.

A series of digital airborne images was collected around solar noon by using a small low speed remotely controlled unmanned airborne vehicle called Pixy® (http://www.drone-pixy.com; Asseline et al., 1999). The digital images were taken at a $150 \mathrm{~m}$ altitude. This yielded a $0.10 \mathrm{~m}$ spatial resolution, and allowed covering the whole study site from one single image to avoid image mosaicking. The digital camera was a Minolta Dimage $7 \mathrm{Hi}$, featuring a 2/3 in. type (equivalent to $17 \mathrm{~mm}$ ) CCD sensor with 5 mega pixels. It collected images with a near nadir viewing through filters centred on $450 \mathrm{~nm}$ (blue), $550 \mathrm{~nm}$ (green) and $650 \mathrm{~nm}$ (red).

\subsection{Ground-based measurements}

A set of ground truth data was acquired each day the drone overpassed. For each day of experiment, half a day was necessary to collect the ground truth data. These reference observations were collected according to a sampling strategy which accounted for the geometrical features of the study site (Corbane et al., 2008). The four fields of the site were split by considering the slope magnitude (Figs. 1 and 2). This yielded partitioning each field into five $20 \mathrm{~m}$ length slope sections that corresponded to $2 \%$ slope intervals between $0 \%$ (downslope) and $10 \%$ (upslope). Then, each slope section was sampled according to the inter row $(2.5 \mathrm{~m})$ and inter stock $(1 \mathrm{~m})$ distances. This yielded four to six $1.25 \mathrm{~m}$ length transects per slope section, and thus 20 to 30 transects per field (Fig. 2). Along each transect, 25 observations were performed with a $5 \mathrm{~cm}$ step, to allocate an SCC attribute according to the instances reported in Table 1 . Next, each

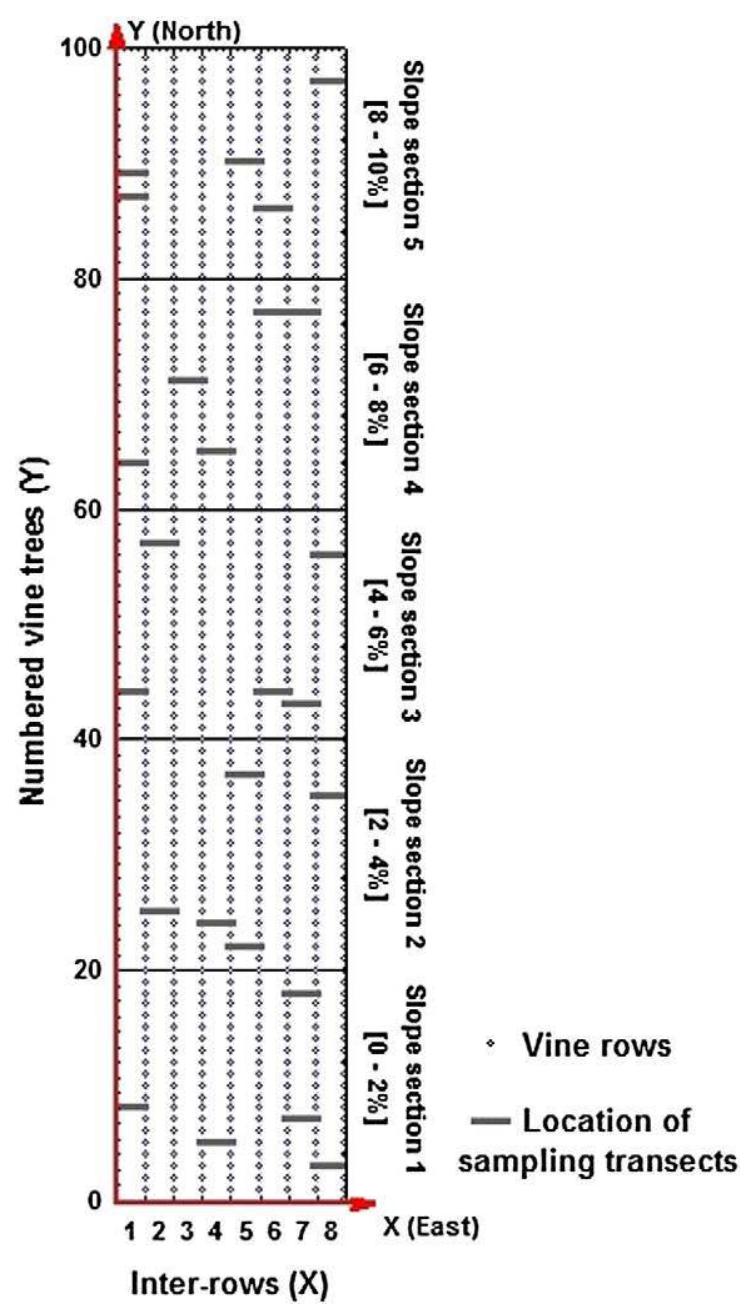

Fig. 2. Illustrative example of the configuration of the grid stratified sampling scheme on Field 1 (Bare Soil controlled by Chemical Weeding). North and east directions are approximated.

transect was assigned to an SSC class according to i) the fraction covers of SSC attributes within the transect and ii) the association rules presented in Table 2 . The corresponding SSC class was supposedly representative of a $0.5 \mathrm{~m}$ width area on each side of the transect. Therefore, each transect provided a ground truth surface of approximately $1 \mathrm{~m}^{2}$ size, and the whole set of transects covered between 1 and $2 \%$ of the whole study area. Finally, the resulting data set (80 to 120 transects assigned to SSC classes for each of the 4 days of experiment) was randomly split into two parts of equal share: one for training the remote sensing-based classification, and the other for assessing the post classification accuracy.

The EOP consisted of collecting ground-based data through 60 transects per field rather than 20 to 30 . For each transect, join count statistics (Cliff and Ord, 1973) were used to test if SSC attributes produced statistically significant $\mathrm{HU}$, and to estimate the size of these HU. Joint count statistics were selected since they were suitable for binary data, in terms of presence or absence of a given SSC attribute. From this extensive experiment, two main results could be reported (Corbane et al., 2008). First, the transect was a suitable support for observing SSC attributes within a row cropped field such as a vineyard. Further, both the transect length $(1.25 \mathrm{~m})$ and sampling (one observation every $5 \mathrm{~cm}$ ) were adequate for detecting spatial heterogeneities of SSC attributes. Second, SSC attributes within transects exhibited significant positive autocorrelations on the assumption of a $10 \%$ type II error, for 40 to $60 \%$ of the considered 


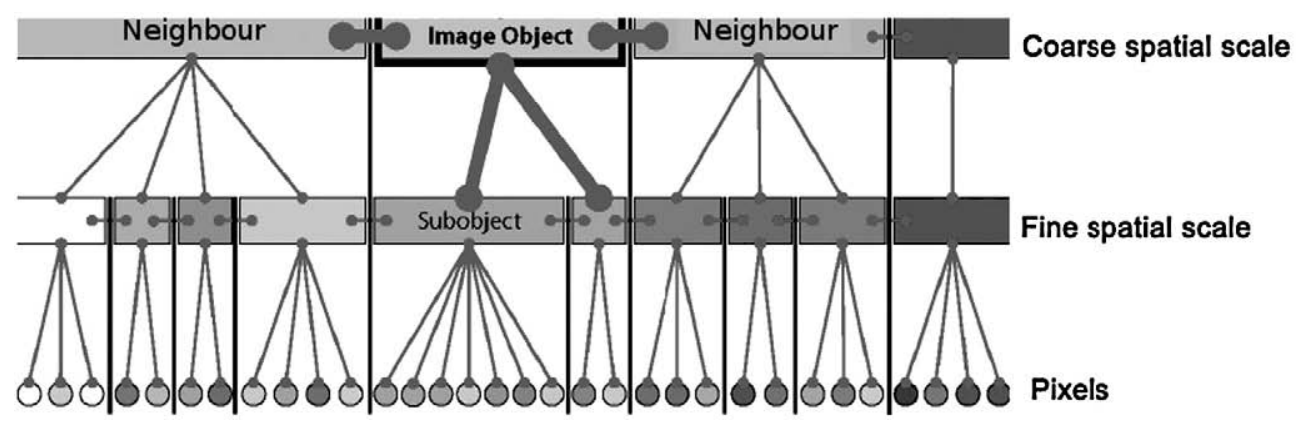

Fig. 3. Hierarchical network of image objects resulting from a two scale segmentation (adapted from Definiens, 2003).

transects. This demonstrated SSC attributes were spatially clustered, whereas their spatial arrangement was homogeneous patches with $0.20 \mathrm{~m}$ to $0.40 \mathrm{~m}$ sizes.

\section{Method and implementation}

The proposed approach relied on the assumption that HU of SSC attributes could be more easily identified from remote sensing images than patches of SSC classes, because of greater homogeneities. This assumption was previously confirmed in Corbane (2006) from ground-based radiometric measurements within a similar Mediterranean landscape. The idea was therefore isolating HU of SSC attributes at a specific fine spatial scale, and then identifying SSC classes at a coarse scale by using the hierarchical network that linked image objects at the two scales (Fig. 3). The relevance of considering two hierarchical scales was previously demonstrated by Corbane et al. (2008) from ground-based measurements within the same experimental site. The problem of SSC delineation was tackled assuming SSC classes depict radiometric homogeneities and can therefore be extracted using a radiometrically based segmentation. The proposed method was implemented for each day of data acquisition, through a three step procedure illustrated in Fig. 4 and detailed below.

After preprocessing raw image data (step 1), an initial multiscale segmentation outlined radiometrically homogeneous regions at two nested spatial scales (step 2). Then, a classification was performed at the two scales (step 3). Individual HU of SSC attributes were identified at the fine scale, through a supervised classification based on nearest neighbour and user selected samples. Next, SSC classes at the coarse scale were assigned using $\mathrm{HU}$ of SSC attributes at the fine scale, along with inter object relations from the hierarchical network. Below is a detailed description of the above defined methodology, as well as its implementation over the database collected from March until July 2004 within the Puisserguier vineyard site.

\subsection{Remote sensing data preprocessing}

Performing SSC classification at several dates previously required radiometrically and geometrically normalizing the images collected at these different dates. Therefore, the preprocessing step of the raw digital airborne images was particularly stressed, including geometric and radiometric corrections. It was finally completed by spatially and radiometrically filtering these images.

In order to superimpose SSC classifications performed at different dates, geometric corrections were compulsory to remove combined distortions from the camera lens, the camera tilt and the topography effects. The radial distortion coefficients and the lens focal length were determined through a camera calibration in laboratory. The camera tilt at snapshot time was characterized from GPS locations of several $25 \times 25 \mathrm{~cm}^{2}$ white targets installed between vine rows each day of experiment. Accounting for these lens and tilt effects, as well as for local topography derived from theodolite measurements, images were finally orthorectified using the standard procedure proposed by Kraus and Waldhaüsl (1998).

In order to compare radiometrically based SSC classifications from one day to another, radiometric corrections were required for normalizing measurements collected at different dates. Such normalization allowed minimizing radiometric variations that might result from experimental factors such as instrumental response, illumination and viewing directions. This was performed to ensure that differences in day to day classification performances were not driven

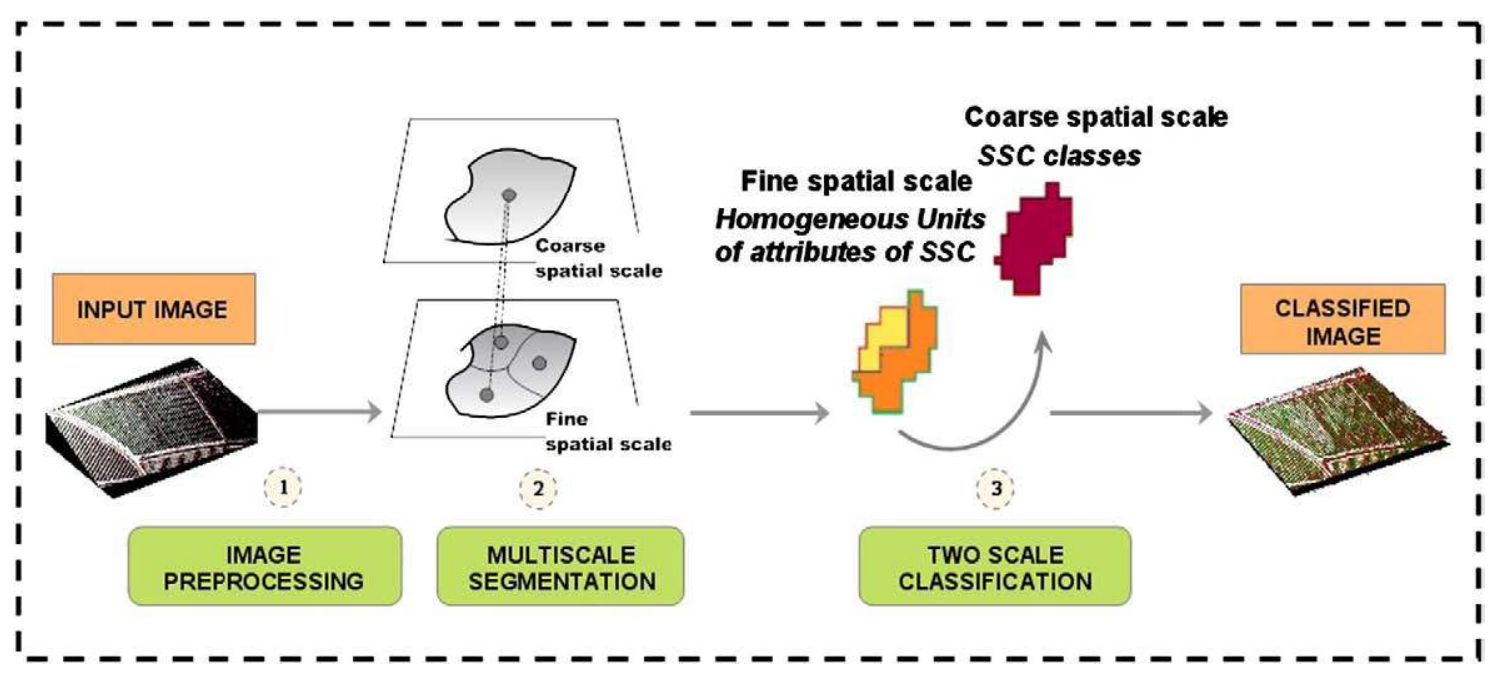

Fig. 4. Flow-chart of the SSC classification methodology. 
by changes in experimental conditions. Radiometric corrections included the removal of sun illumination effects, and an inter calibration of surface reflectances. In order to account for differences in sun illumination from one date to another, we applied the correction proposed by Richter and Schlaepfer (2002). The latter is based on the sun zenith angle and assumes isotropic reflection (Shoshany, 1992, 2000). Surface reflectances at the various dates were inter calibrated using a linear correction derived from two sets of horizontal and homogeneous objects within the study area. The white squared targets were used as control set for large surface reflectances, and the central section of the gutters installed downstream of each parcel were used as control set for low surface reflectance.

Following Wassenaar et al. (2005), it was necessary removing vine canopy and corresponding shadow. Indeed, vine canopy was not related to soil surface characteristics, while shadow could perturb radiometrically based classification. Removal was performed using radiometric thresholding on red reflectance, where the threshold was day dependent according to soil surface conditions and vineyard temporal evolution.

\subsection{Multiscale segmentation}

A multiscale segmentation was applied for creating image objects at two nested spatial scales: a fine scale for characterizing HU of SSC attributes and a coarse scale for characterizing hydrological SSC classes. For this, the radiometric information provided within the three wavebands was merged through a linear combination. The latter assigned a larger weight to red reflectance (0.6) as compared to blue and green ones ( 0.2 each), given red reflectance could be considered as the main source of information for discriminating most of mineral SSC (Wassenaar et al., 2005).

The multiscale segmentation technique selected for the current study was the Fractal Net Evolution Approach (Baatz and Schape, 2000; Definiens, 2003; Gamanya et al., 2007). A detailed description of this segmentation procedure is given in Benz et al. (2004). FNEA consists of a bottom up merging technique from pixels to objects: smaller objects are merged into larger ones through a pairwise clustering process which maximizes the homogeneity of the resulting objects through a dissimilarity threshold. The latter is calculated as a linear combination of radiometric heterogeneity (expressed through the variance over pixels within a given object) and form heterogeneity (expressed through compactness and smoothness). The definition of homogeneity is therefore flexible and consists of a trade-off between radiometric variability and spatial form/shape (Carleer et al., 2005). The balance at which these two criteria apply depends on the desired output (Thomas et al., 2003) and enables adjusting segmentation according to the considered application (Willhauck, 2000). The control of a segmentation scale, and therefore of the resulting average size for the generated objects, is operated through the scale factor that corresponds to a threshold of heterogeneity criterion between image objects (Thomas et al., 2003). Several segmentations can be performed by modifying the scale factor. This allows image representations at different scales, where the objects generated at a given scale inherit the information of smaller objects at the finer scales and vice versa.

Given the scale factor significantly influences the selection of each spatial scale for the multiscale segmentation, scale factor values have to be determined by reducing any potential subjectiveness. For the current study, two scale factors were targeted, corresponding to spatial scales for both HU of SSC attributes and patches of SSC classes. Both HU and patches were supposed structuring the considered images at their corresponding spatial scales. In order to identify these spatial scales, segmentations at various scales were performed by varying scale factor over the whole range of possibilities (from 1 to 100 ). This yielded a growth curve that characterized the object mean length as a function of scale factor, where the object mean length was estimated from those of skeleton main lines. We choose the object mean length as indicator, since it allowed a straight comparison between segmentation results and field observations, in terms of determining specific spatial scales through lengths. Stable periods, hereafter called stability zones, were next identified on the growth curve as the scale factor intervals with the lowest variations of object mean length, corresponding to structuring levels in the image (Mori et al., 2004). For the fine scale, the scale factor had to correspond to the object mean length close to the averaged size of HU of SSC attributes. This correspondence was next verified using the ground-based data collected during the EOP in may 2004 (see Section 3.3). For the coarse scale, the scale factor had to correspond to an average length larger than that obtained at the fine scale. Each of the two targeted scale factors was finally selected as the minimum value within the corresponding stability zone. The framework presented here (growth

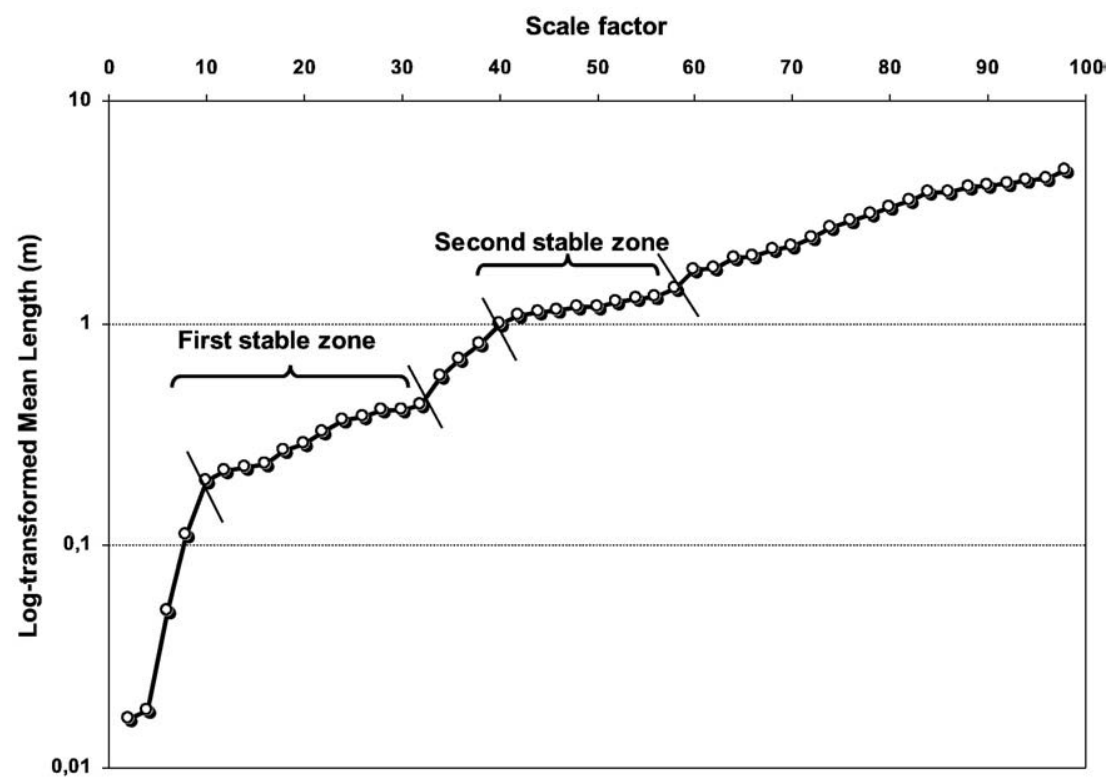

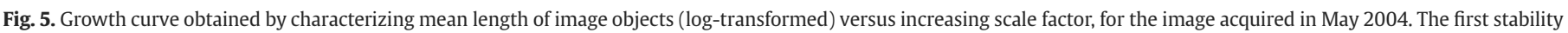
zone is observed at scale factors comprised between 10 and 32, the second stability zone at scale factors comprised between 40 and 58 . 
curve generation, stability zone identification, scale factor selection) was applied for each day of airborne data collection, allowing the selection of the two spatial scales from the multiscale segmentation.

\subsection{Two scale classification}

Once the multiscale segmentation was performed, the two scale classification consisted of assigning i) a HU of SSC attribute to a given object at the fine spatial scale and ii) a SSC class to a given object at the coarse scale. A detailed description of the object-oriented image classification paradigm is given in Platt and Rapoza (2008).

Assigning $\mathrm{HU}$ of SSC attributes at the fine spatial scale was performed using a nearest neighbour classifier in an object-oriented framework along with user selected training sets, similarly to a supervised classification on a pixel basis. The advantage was the easy and fast training from a limited number of samples (Hardin and Thomson, 1992; Matinfar et al., 2007), while incorporating radiometric and spatial criteria for discriminating different HU of SSC attributes. The training was performed using half of the ground-based observations, while the other half was further used for assessing the post classification accuracy (see Section 3.3). The best combination between radiometric (i.e. object averaged reflectance over blue, green and red wavebands) and spatial (i.e. length, texture) criteria was automatically quested from the training set (Definiens, 2003). For this, a multi criteria optimization used the minimum distance as the measure of dissimilarity among different classes (Solberg and Egeland, 1993). This finally yielded each object at the fine spatial scale to be classified according to the HU of SSC attributes from Table 1: litter, grass cover, structural crust, sedimentary crust, large clods for recently tilled soils or small clods with a slightly sealed surface.

The identification of SSC classes was next performed at the coarser spatial scale. At this scale, an object was a spatial extent containing several HU of different SSC attributes. Each object was then assigned to a given SSC class, by using the fine scale classification results, along with the spatial relations between the two scales within the object hierarchy. For this purpose, a set of decision rules was implemented, following those designed when characterizing ground-based estimates of SSC (Table 2). These decision rules referred to the fine scale classification, as explicit with the following example: if the fraction cover for $\mathrm{HU}$ of litter ranged between 0.5 and 1 and that for $\mathrm{HU}$ of structural crust ranged between 0.1 and 0.5 , then the resulting SSC class was "LC", which corresponded to an infiltration rate of about $18 \mathrm{~mm} / \mathrm{h}$.

\section{Results}

Fig. 5 displays an example of growth curve obtained when characterizing the object mean length (log-transformed) as a function of scale factor, where the latter ranges from 1 to 100 . For the considered day in May 2004, the object mean length grew exponentially with the scale factor, ascertaining a larger scale factor results in larger image objects (Benz et al., 2004). Then, two stability zones could be observed for the [10-32] and [40-58] scale factor intervals. For the [10-32] interval, the object mean length ranged

Table 3

Scale factors used for the multiscale segmentation of image data

\begin{tabular}{|c|c|c|c|c|}
\hline \multirow[t]{3}{*}{ Image date } & \multicolumn{2}{|c|}{ Fine spatial scale } & \multicolumn{2}{|c|}{ Coarse spatial scale } \\
\hline & \multicolumn{2}{|c|}{$\mathrm{HU}$ of SSC attributes } & \multicolumn{2}{|l|}{ SSC classes } \\
\hline & Scale factor & Object mean length & Scale factor & Object mean length \\
\hline 27 March 2004 & 10 & From 0.2 to $0.3 \mathrm{~m}$ & 40 & From 1 to $1.4 \mathrm{~m}$ \\
\hline 18 May 2004 & 10 & From 0.2 to $0.4 \mathrm{~m}$ & 40 & From 1 to $1.5 \mathrm{~m}$ \\
\hline 15 June 2004 & 14 & From 0.3 to $0.6 \mathrm{~m}$ & 42 & From 1.1 to $1.4 \mathrm{~m}$ \\
\hline 23 July 2004 & 14 & From 0.4 to $0.7 \mathrm{~m}$ & 46 & From 1.1 to $1.8 \mathrm{~m}$ \\
\hline
\end{tabular}

Table 4

Set of best criteria used for the classification of HU of litter, sedimentary crust, structural crust, large clods and grass on the image acquired in May 2004

\begin{tabular}{lll}
\hline Criteria & Radiometric & Spatial \\
\hline Red band mean value & $\mathrm{X}$ & \\
Standard deviation (red band) & $\mathrm{X}$ & \\
Ratio (red band) & $\mathrm{X}$ & \\
Mean difference to neighbours & $\mathrm{X}$ & $\mathrm{X}$ \\
Relative boarder to brighter neighbours & $\mathrm{X}$ & $\mathrm{X}$ \\
Brightness $_{\text {GLCM }^{\mathrm{a}} \text { mean (red band) }}^{\mathrm{X}}$ & $\mathrm{X}$ \\
Shape index & $\mathrm{X}$ & $\mathrm{X}$ \\
\hline
\end{tabular}

These criteria were obtained using a multi criteria optimization approach, and computed on image objects rather than on single pixels. Ratio (red band) stands for the ratio of mean radiometry over an image object within the red band to the sum of mean radiometries over an image object within all considered bands (here blue, green and red). For a full description of computation, refer to Definiens manual (2003). a GLCM: The grey level co-occurrence matrix.

between $0.2 \mathrm{~m}$ and $0.4 \mathrm{~m}$. This corresponded to the average length of HU of SSC attributes observed when analysing in situ spatial variability of SSC attributes (Corbane et al., 2008). For the [40-58] scale factor interval, the object mean length ranged between $1 \mathrm{~m}$ and $1.5 \mathrm{~m}$. This corresponded to the average length set up in the field for assigning aggregates of SSC attributes to SSC classes. These results corroborated the suitability of the proposed strategy for selecting the scale factors through the growth curve concept. For the example displayed in Fig. 5, selecting the minimum value for each stability zone yielded considering a scale factor of 10 (respectively 40) for the fine (respectively coarse) spatial scale. We did not seek other specific stability zone at larger scales, since the spatial structuring was then predominantly influenced by vine inter row.

Table 3 displays the selected scale factors and corresponding object mean lengths for each day the drone overpassed. It is shown image object mean lengths at both fine and coarse spatial scales were generally stable, with small variations between May and June for fine scale, and between June and July for coarse scale. These variations might be related to changes in grass fraction cover during spring and summer. Such seasonal changes in object mean length demonstrated the need for a fine temporal sampling of spatial variability of SSC attributes, in order to determine changes in patch size.

Table 4 displays an example for the most suitable set of radiometric and spatial criteria, when classifying $\mathrm{HU}$ of SSC attributes from the image acquired in May 2004. As evidenced by the multi criteria optimization approach, radiometric and spatial criteria had to be jointly considered for an effective separability between HU of SSC attributes. Fig. 6 exhibits the images classified into the main SSC classes, spanning from March to July 2004 over the Puisserguier vineyard. We observed significant heterogeneities, both in time between the four date and in space between fields. Sub field variability could also be observed. However, a spatial structuring of SSC within the same field prevailed, and was more or less manifest according to image acquisition date.

Table 5 displays, for the four classified images, the accuracy assessments from confusion (classification-error) matrices, Kappa statistics, overall and producer accuracies. Classification accuracy means here the level of agreement between SSC classes assigned using i) remotely sensed images along with the two scale classification, and ii) the ground-based class allocation from the in situ data subset devoted to validation (Section 3.3). On March, overall classification accuracy was $80 \%$. On May, the classification results were slightly better with an overall accuracy of $84 \%$. On June and July, we observed a decrease of the overall accuracy that fell down to 69\% in June and to $63 \%$ in July. When examining the results by SSC class in terms of producer accuracy, good performances were systematically observed for STC and T, although T class occurred on May only. Intermediate performances were observed for TC on the two dates this class 

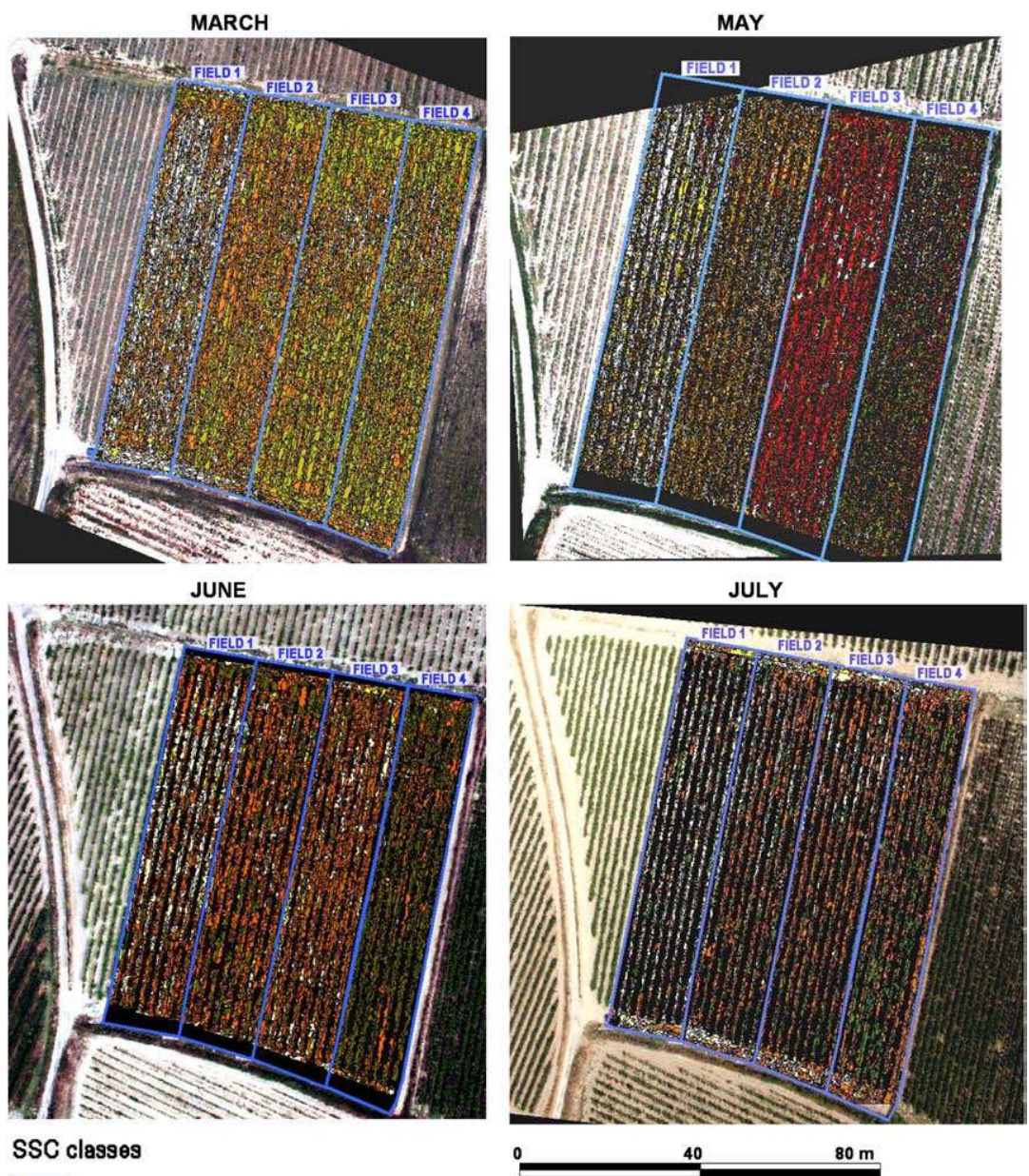

SSC classes

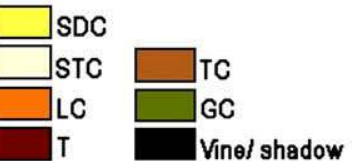

Fig. 6. SSC classification outputs for the images acquired between March and July 2004

occurred. Poor performances were systematically observed for SDC Variable performances were obtained for GC (respectively LC) with large producer accuracy values on March, May and June (respectively March and May). The main confusions were observed between LC and TC on June, GC and LC on July, and between STC and SDC on all dates.

\section{Discussion}

The increasing of overall accuracy from March to May could be explained by a tillage operation between both dates. Indeed, tillage induced the apparition of the T class, which was easily discriminated because of specific texture and radiometric behaviour related to surface roughness. The good performances (overall accuracies larger than 80\%) observed in March and May decreased in June and July (overall accuracies lower than 70\%), because of three factors. First, $\mathrm{T}$ class (recently tilled surfaces) changed into TC class (previously tilled surfaces slightly sealed). This might induce slight confusions with STC and SDC classes (completely sealed surfaces with well-formed surface crusts), assuming the three classes differed more by their sealing degree than by their mineral composition (Bresson and Boiffin, 1990). Second, confusions were observed between TC and LC, with over detection of LC into TC on June and reversely on July. No consistent explanation could be found for both the confusions and the reverse trend. Third, confusions between GC and LC classes were more important in June and especially July, because of closer spectral behaviour between senescent grass and litter. Indeed, most of the grass cover became senescent in summer time and thus progressively changed from green to yellow vegetation, making difficult the distinction between senescent grass and litter (Jia et al., 2006).

Apart from the confusions reported above, important misclassifications were observed for SDC class. This was linked to confusions between STC and SDC classes, because of similar mineral compositions that induced small differences between both classes in terms of textures and radiometric behaviours. Regardless of considered date, these confusions had negligible impacts on STC classification performances, but significant consequences on SDC classification performances. This resulted from large differences between class occurrences, given STC class occurrence was always significantly larger than that of SDC class over the considered study area. Thus, for the June imagery, a similar number of confused pixels (613 versus 667) yielded producer accuracies of $84 \%$ for STC and 14\% for SDC.

As compared to the BRDF-based classification proposed by Wassenaar et al. (2005), we globally observed similar performances in terms of class discrimination between TC, GC, SDC and STC. We observed with our method slightly better differentiations between $\mathrm{T}$ and LC classes. Indeed, these classes were separable from multiangular information under specific illumination conditions only, which might alter the identification of the other SSC classes. Similarly to the method proposed by Wassenaar et al. (2005), important confusions unfortunately remained between SDC and STC classes. 
Table 5

Error matrices for the four days of experiment

\begin{tabular}{|c|c|c|c|c|c|c|c|}
\hline & & \multicolumn{6}{|c|}{ Reference data } \\
\hline & & STC & SDC & GC & LC & $\mathrm{T}$ & TC \\
\hline \multicolumn{8}{|l|}{$\mathrm{a}-$ March } \\
\hline \multirow[t]{8}{*}{ Classified data } & STC & 3601 & 788 & 0 & 44 & $\mathrm{~N} / \mathrm{A}$ & $\mathrm{N} / \mathrm{A}$ \\
\hline & SDC & 539 & 138 & 0 & 0 & $\mathrm{~N} / \mathrm{A}$ & $\mathrm{N} / \mathrm{A}$ \\
\hline & GC & 66 & 0 & 9741 & 27 & $\mathrm{~N} / \mathrm{A}$ & $\mathrm{N} / \mathrm{A}$ \\
\hline & LC & 963 & 98 & 1379 & 2777 & $\mathrm{~N} / \mathrm{A}$ & $\mathrm{N} / \mathrm{A}$ \\
\hline & $\mathrm{T}$ & $\mathrm{N} / \mathrm{A}$ & N/A & $\mathrm{N} / \mathrm{A}$ & $\mathrm{N} / \mathrm{A}$ & $\mathrm{N} / \mathrm{A}$ & $\mathrm{N} / \mathrm{A}$ \\
\hline & TC & $\mathrm{N} / \mathrm{A}$ & $\mathrm{N} / \mathrm{A}$ & $\mathrm{N} / \mathrm{A}$ & $\mathrm{N} / \mathrm{A}$ & $\mathrm{N} / \mathrm{A}$ & $\mathrm{N} / \mathrm{A}$ \\
\hline & Producer accuracy & 0.70 & 0.13 & 0.88 & 0.98 & $\mathrm{~N} / \mathrm{A}$ & $\mathrm{N} / \mathrm{A}$ \\
\hline & Overall accuracy: & 0.80 & \multicolumn{3}{|c|}{ Kappa coefficient: } & 0.69 & \\
\hline \multicolumn{8}{|l|}{ b - May } \\
\hline \multirow[t]{9}{*}{ Classified data } & STC & 8169 & 485 & 127 & 56 & 258 & $\mathrm{~N} / \mathrm{A}$ \\
\hline & SDC & 2119 & 816 & 8 & 95 & 0 & $\mathrm{~N} / \mathrm{A}$ \\
\hline & GC & 0 & 0 & 3087 & 11 & 100 & $\mathrm{~N} / \mathrm{A}$ \\
\hline & LC & 50 & 0 & 140 & 9297 & 283 & $\mathrm{~N} / \mathrm{A}$ \\
\hline & $\mathrm{T}$ & 36 & 0 & 94 & 430 & 5194 & $\mathrm{~N} / \mathrm{A}$ \\
\hline & $\mathrm{TC}$ & $\mathrm{N} / \mathrm{A}$ & $\mathrm{N} / \mathrm{A}$ & $\mathrm{N} / \mathrm{A}$ & $\mathrm{N} / \mathrm{A}$ & $\mathrm{N} / \mathrm{A}$ & $\mathrm{N} / \mathrm{A}$ \\
\hline & Unclassified & 142 & 0 & 0 & 0 & 0 & $\mathrm{~N} / \mathrm{A}$ \\
\hline & Producer accuracy & 0.77 & 0.62 & 0.89 & 0.91 & 0.89 & $\mathrm{~N} / \mathrm{A}$ \\
\hline & Overall accuracy: & 0.84 & \multicolumn{3}{|c|}{ Kappa coefficient: } & 0.74 & \\
\hline \multicolumn{8}{|l|}{$c$ - June } \\
\hline \multirow[t]{9}{*}{ Classified data } & STC & 5394 & 667 & 0 & 472 & $\mathrm{~N} / \mathrm{A}$ & 509 \\
\hline & SDC & 613 & 110 & 0 & 0 & $\mathrm{~N} / \mathrm{A}$ & 39 \\
\hline & GC & 0 & 0 & 1967 & 236 & $\mathrm{~N} / \mathrm{A}$ & 0 \\
\hline & LC & 0 & 0 & 159 & 1691 & $\mathrm{~N} / \mathrm{A}$ & 303 \\
\hline & $\mathrm{T}$ & $\mathrm{N} / \mathrm{A}$ & $\mathrm{N} / \mathrm{A}$ & $\mathrm{N} / \mathrm{A}$ & $\mathrm{N} / \mathrm{A}$ & $\mathrm{N} / \mathrm{A}$ & $\mathrm{N} / \mathrm{A}$ \\
\hline & $\mathrm{TC}$ & 143 & 0 & 49 & 1361 & $\mathrm{~N} / \mathrm{A}$ & 1858 \\
\hline & Unclassified & 294 & 0 & 0 & 74 & $\mathrm{~N} / \mathrm{A}$ & 0 \\
\hline & Producer accuracy & 0.84 & 0.14 & 0.90 & 0.44 & $\mathrm{~N} / \mathrm{A}$ & 0.69 \\
\hline & Overall Accuracy: & 0.69 & \multicolumn{3}{|c|}{ Kappa coefficient: } & 0.58 & \\
\hline \multicolumn{8}{|l|}{ d - July } \\
\hline \multirow[t]{9}{*}{ Classified data } & STC & 3651 & 621 & 0 & 54 & $\mathrm{~N} / \mathrm{A}$ & 660 \\
\hline & SDC & 0 & 293 & 0 & 0 & $\mathrm{~N} / \mathrm{A}$ & 0 \\
\hline & GC & 300 & 0 & 1867 & 706 & $\mathrm{~N} / \mathrm{A}$ & 56 \\
\hline & LC & 38 & 196 & 1466 & 1157 & $\mathrm{~N} / \mathrm{A}$ & 843 \\
\hline & $\mathrm{T}$ & $\mathrm{N} / \mathrm{A}$ & $\mathrm{N} / \mathrm{A}$ & $\mathrm{N} / \mathrm{A}$ & $\mathrm{N} / \mathrm{A}$ & $\mathrm{N} / \mathrm{A}$ & $\mathrm{N} / \mathrm{A}$ \\
\hline & TC & 51 & 102 & 0 & 58 & $\mathrm{~N} / \mathrm{A}$ & 2331 \\
\hline & Unclassified & 0 & 0 & 159 & 17 & $\mathrm{~N} / \mathrm{A}$ & 0 \\
\hline & Producer accuracy & 0.90 & 0.24 & 0.53 & 0.58 & $\mathrm{~N} / \mathrm{A}$ & 0.60 \\
\hline & Overall accuracy: & 0.63 & \multicolumn{3}{|c|}{ Kappa coefficient: } & 0.53 & \\
\hline
\end{tabular}

N/A means the considered class was not included within the study area for the day of data acquisition. The pixel numbers for the ground truth data refer to "Reference data", and the pixel numbers for the remotely sensing-based estimates refer to "Classified data".

Given the significant differences in infiltration rates for SDC and STC classes, it seems necessary distinguishing these classes, which remains a critical issue. Conclusively, our expectations about potentials of adjoining radiometric and spatial remotely sensed information were not satisfied, in terms of differentiating these two specific hydrological SSC classes.

In spite of similar performances, the radiometry-spatial-based approach proposed here remains more promising in terms of improvement and portability than the BRDF-based method proposed by Wassenaar et al. (2005). Potential improvements include the extension of the spectral range to the whole solar spectrum, and the consideration of multispectral or hyperspectral observations. In terms of portability, it is technically easier collecting and using observations from multispectral sensors than from goniometric systems or multiangular imagers, especially for data processing such as image superimposition. This makes the approach proposed here more suitable for mapping and monitoring SSC classes, since it can be more easily transposed in time and space.

Thanks to a large flexibility, two ways may be investigated for improving the method we proposed here. The first way of improvement is using richer spectral information to better differentiate the ambiguously classified SSC classes. For example, the SWIR region over the [1.2-2.5] $\mu \mathrm{m}$ range has been proven to be useful for determining changes in the structural crust formation (Goldshleger et al., 2001). Using this spectrum could probably help distinguishing between structural and sedimentary crusts, although measuring at a fine spatial resolution is technically not obvious (Heiden et al., 2007). Also, observations across the NIR and SWIR regions are valuable for detecting spectral changes of crusted soils, for discriminating tilled surfaces, and for differentiating crusted and non-crusted surfaces (Cierniewski, 1989; Chappell et al., 2005). Finally, high spectral resolution across SWIR region can be useful for characterizing structural, sedimentary and biological crusts (Weber et al., 2008; Anderson and Kuhn, 2008; Goldshleger et al., 2002). The second way of improvement is overcoming the problem of classification refinement by using ancillary knowledge about changes in SSC related to precipitations. This may be found in field studies about SSC under natural or simulated rainfall (Andrieux et al., 2001). The proposed procedure, in its current stand structure, is sufficiently versatile to allow incorporating this type of temporal information in a expert multi-date classification, in the context of SSC temporal monitoring.

Though we tested the method on four different fields at four dates in order to maximize its representativeness, some SSC classes from the typology of Andrieux et al. (2001) were not included within the study area. It is therefore recommended to extend the method to other fields with a stony soil texture subject to different soil management practices, to confirm its applicability and performance. Similarly, the method was successfully applied since the growth curve provided object dimension values very similar to those observed from groundbased data. However, such conclusive investigations have to be confirmed over different landscapes that can induce other influences when isolating object dimensions from the growth curve. Finally, the method was applied within a Mediterranean semiarid context after drying periods, making the impact of soil moisture negligible. When considering neither arid nor semiarid contexts, lower occurrences of drying periods significantly constrain the method implementation. A possible solution is then considering soil moisture effects through SWIR wavebands that are sensitive to water absorption.

Finally, a fine spatial resolution was mandatory for the detection of SSC in the vineyard inter row. However, the mapping approach is not only limited to fine resolutions. It can also be applied to lower spatial resolutions such as those offered by satellite images. The latter are probably more adequate for the detection of SSC in agricultural environments with annual crops and with a continuous vegetation cover. Applied on Very High spatial Resolution (VHR) satellite images such as those collected by IKONOS or QuickBird, the approach may then be easily used for monitoring SSC on larger areas and under different soil management and cultivation conditions. This was already tested with the $2.5 \mathrm{~m}$ spatial resolution SPOT 5 imagery over a small Tunisian catchment characterized by different soil management and cultivation conditions (Corbane, 2006).

\section{Conclusion}

The current study aimed at using very high spatial resolution solar remote sensing for the mapping of hydrological soil surface characteristics (SSC) over Mediterranean vineyards. According to previous works that investigated the potential of multiangular information, the originality of the approach proposed here consisted of using radiometric and spatial information. This was performed through a multiscale segmentation followed by a two scale classification. The fine scale was related to Homogeneous Units (HU) of attributes that composed hydrological SSC (soil micro topography, surface crust types and soil cover). The coarse scale was related to hydrological SSC classes that included patchworks of attributes. Both fine and coarse scales were derived by analysing the growth curve which resulted from the multiscale segmentation. 
The proposed method was assessed over a wide range of management practices for Mediterranean vineyards. The results showed acceptable performances with overall accuracy ranging from 63 to $84 \%$, depending on SSC classes and surface conditions that changed with day of experiment. However, these performances were not significantly better than those reported by Wassenaar et al. (2005) when investigating the potential of multiangular observations over similar vineyards. Given important hydrological SSC classes still remained undifferentiated, our expectations were therefore moderately satisfied when using spatial and radiometric information in place of multiangular observations. Nevertheless, the combined use of radiometric and spatial information provide a wider range of improvement possibilities as compared to the use of multiangular data.

The main advantages of using radiometric and spatial data in place of multiangular observations are twofold, in terms of improvement and portability. Possible improvement involved spectral and temporal information. Using spectral information can be easily strengthened by broadening the considered spectral range. Thus, future investigations should focus on benefiting from the near infrared (around $0.8 \mu \mathrm{m}$ ) and the shortwave infrared (from 1.2 to $2.5 \mu \mathrm{m}$ ) spectral ranges, including multispectral or hyperspectral observations. Another possible improvement relies on incorporating ancillary knowledge about SSC evolution derived from in situ information. In terms of portability, avoiding complex observation systems such as goniometers or multiangular imagery allows easier transpositions in time and space. The proposed framework can therefore be considered as an initial step towards building a semi-automated procedure, in order to obtain information on SSC at very high spatial and temporal resolutions as required by the distributed hydrological models.

Finally, multiscale approaches alternative to Fractal Net Evolution Approach were developed during the last decade, such as Linear Scale Space (Lindeberg, 1994) and Size Constrained Region Merging (Castilla et al., 2008). Though these approaches differ from a theoretical point of view, they focus on the analysis of intrinsic patterns within a single image and on the multiscale exploration of image objects. New operational segmentation methods based on these alternative approaches are now available, such as the Multiscale Object-Specific Segmentation (Hay et al., 2005). These methods have to be assessed and compared, since they can potentially reduce the exploratory works needed to define the appropriate segmentation levels. This is especially true when conducting baseline analysis without any a priori information about SSC characteristic scales (Hay et al., 2003).

\section{Acknowledgments}

We express our profound gratitude to Dr. J.-M. Robbez Masson who made a significant contribution to this work before he passed away on July 2005. We are thankful to Mr. Jean Asseline for his assistance in collecting the airborne images. We also thank technicians of LISAH (Laboratory of studies about Interactions between Soil-AgrosystemHydrosystem) for their participation in the field campaigns. This research was supported by "XIle Contrat de Plan Etat Région-LR" and a $\mathrm{PhD}$ studentship granted to $\mathrm{C}$. Corbane by IRD (Institute of Research for the Development).

\section{References}

Anderson, K., Kuhn, N.J., 2008. Variations in soil structure and reflectance during a controlled crusting experiment. International Journal of Remote Sensing 29 (12), 3457-3475.

Andrieux, P., Hatier, A., Asseline, J., de Noni, G., Voltz, M., 2001. Predicting infiltration rates by classifying soil surface features in a Mediterranean wine-growing area. Ora communication. International Symposium "The Significance of Soil Surface Characteristics in Soil Erosion. COST 623 "Soil Erosion and Global Change" workshop, Strasbourg.

Asseline, J., Valentin, C., 1978. Construction et mise au point d'un infiltromètre à aspersion. Cahiers ORSTOM. Série Hydrologie 15 (4), 321-349.

Asseline, J., De Noni, G., Chaume, R., 1999. Note sur la conception et l'utilisation d'un drone lent pour la télédétection rapprochée. Photo Interprétation 37, 3-9.
Auzet, A.V., Boiffin, J., 1995. Concentrated flow erosion in cultivated catchments: influence of soil surface state. Earth Surface Processes and Landforms 20, 759-769.

Baatz, M., Schape, A., 2000. Multiresolution segmentation: an optimization approach for high quality multi-scale image segmentation. In: Strobl, J., Blaschke, T., Griesebner G. (Eds.), Angewandte Geographische Informationsverarbeitung, vol. XII. WichmannVerlag, Heidelberg, pp. 12-23.

Baghdadi, N., King, C., Bourguignon, A., Remond, A., 2002. Potential of ERS and Radarsat data for surface roughness monitoring over bare agricultural fields: application to catchments in Northern France. International Journal of Remote Sensing 23 (17), 3427-3442.

Ben-Dor, E., Irons, J.R., Epema, G.F., 1999. Soil reflectance. In: Rencz, A.E. (Ed.), Remote Sensing for the Earth Sciences. Manual of Remote Sensing, vol. 3. John Wiley \& Sons, New York, pp. 111-188

Ben-Dor, E., Goldlshleger, N., Benyamini, Y., Agassi, M., Blumberg, D.G., 2003. The spectral reflectance properties of soil structural crusts in the $1.2-$ to $2.5-\mu \mathrm{m}$ spectral region. Soil Science Society of America Journal 67, 289-299.

Ben-Dor, E., Goldshleger, N., Braun, O., Kindel, B., Goetz, A.F.H., Bonfil, D., Margalit, N., Benyamini, Y., Karnieli, A., Agassi, M., 2004. Monitoring infiltration rates in semiarid soils using airborne hyperspectral technology. International Journal of Remote Sensing 25 (13), 2607-2624.

Benz, U.C., Hofmann, P., Willhauck, G., Lingenfelder, I., Heynen, M., 2004. Multi-resolution, object-oriented fuzzy analysis of remote sensing data for GIS-ready information. ISPRS Journal of Photogrammetry and Remote Sensing 58 (3-4), 239-258.

Bock, M., Xofis, P., Mitchley, J., Rossner, G., Wissen, M., 2005. Object-oriented methods for habitat mapping at multiple scales - case studies from Northern Germany and Wye Downs, UK. Journal for Nature Conservation 13 (2-3), 75-89.

Bresson, L.M., Boiffin, J., 1990. Morphological characterization of soil crust development stages on an experimental field. Geoderma 47, 301-325.

Carleer, A.P., Debeir, O., Wolff, E., 2005. Assessment of very high spatial resolution satellite image segmentations. Photogrammetric Engineering \& Remote Sensing 71 (11), 1285-1294.

Casenave, A., Valentin, C., 1992. A runoff capability classification system based on surface features criteria in semi-arid areas of West Africa. Journal of Hydrology 130, 231-249.

Castilla, G., Hay, G.J., Ruiz-Gallardo, J.R., 2008. Size-constrained region merging (SCRM): an automated delineation tool for assisted photo interpretation. Photogrammetric Engineering and Remote Sensing 74, 409-419.

Cerdan, O., Souchère, V., Lecomte, V., Couturier, A., Le Bissonnais, Y., 2001. Incorporating soil surface crusting processes in an expert-based runoff and erosion model: STREAM (Sealing and Transfer by Runoff and Erosion related to Agricultural Management). Catena 46, 189-205.

Chappell, A., Zobeck, T.M., Brunner, G., 2005. Using on-nadir spectral reflectance to detect soil surface changes induced by simulated rainfall and wind tunnel abrasion. Earth Surface Processes and Landforms 30, 489-511.

Cierniewski, J., 1989. The influence of the viewing geometry of bare rough soil surfaces on their spectral response in the visible and near-infrared range. Remote Sensing of Environment 27, 135-142.

Clegg, Z., Farres, P., Poesen, J., 1999. Soil surface drip point features: an integrated approach using analytical photogrammetry and soil micromorphology. Catena 35 (2-4), 303-316.

Cliff, A.D., Ord, J.K., 1973. Spatial Autocorrelation. Pion, London. 178 pp.

Corbane, C., 2006. Detection of soil surface characteristics in Mediterranean agricultural areas by remote sensing at very high spatial resolution. PhD dissertation, University of Montpellier II, $251 \mathrm{pp}$.

Corbane, C., Andrieux, P., Voltz, M., Chadoeuf, J., Albergel, J., Robbez Masson, J.M., Zante, P., 2008. Assessing the variability of soil surface characteristics in row-cropped fields: the case of Mediterranean vineyards in Southern France. Catena 72 (1), 79-90.

De Jong, S.M., 1992. The analysis of spectroscopical data to map soil types and soil crusts of Mediterranean eroded soils. Soil Technology 5, 199-211.

Definiens, 2003. eCognition User Guide, vol. 3, pp. 3-28.

Descroix, L., Viramontes, D., Vauclin, M., Gonzalez Barrios, J.L., Esteves, M., 2001. Influence of soil surface features and vegetation on runoff and erosion in the Western Sierra Madre/Durango, Northwest Mexico. Catena 43, 115-135.

Descroix, L., Gonzalez Barrios, J.L., Vandervaere, J.P., Viramontes, D., Bollery, A., 2002. An experimental analysis of hydrodynamic behaviour on soils and hillslopes in a subtropical mountainous environment (Western Sierra Madre, Mexico). Journal of Hydrology 266 (1-2), 1-14

Dunne, T., Zhang, W., Aubry, B.F., 1991. Effects of rainfall, vegetation and microtopography on infiltration and runoff. Water Resources Research 27, 2271-2285.

Escadafal, R., Bacha, S., 1996. Strategy for the dynamic study of desertification. Proceedings of the ISSS International Symposium Ouagadougou, Burkino Faso, pp. 19-34.

Eshel, G., Levy, G.J., Singer, M.J., 2004. Spectral reflectance properties of crusted soils under solar illumination. Soil Science Society of America Journal 68, 1982-1991.

Gamanya, R., De Maeyer, P., De Dapper, M., 2007. An automated satellite image classification design using object-oriented segmentation algorithms: a move towards standardization. Expert Systems with Applications 32 (2), 616-624.

Goldshleger, N., Ben-Dor, E., Benyamini, Y., Agassi, M., Blumberg, D.G., 2001. Characterization of soil's structural crust by spectral reflectance in the SWIR region (1.5-2.5 um). Terra Nova 13 (1), 12-17.

Goldshleger, N., Ben-Dor, E., Benyamini, Y., Blumberg, D.G., Agassi, M., 2002. Spectral properties and hydraulic conductance of soil crusts formed by raindrop impact. International Journal of Remote Sensing 23, 3909-3920.

Goldshleger, N., Ben-Dor, E., Benyamini, Y., Agassi, M., 2004. Soil reflectance as a tool for assessing physical crust arrangement of four typical soils in Israel. Soil Science 169 (10), 677-687.

Govers, G., Takken, I., Helming, H., 2000. Soil roughness and overland flow. Agronomie 20 (2), 131-146. 
Hardin, P.J., Thomson, C.N., 1992. Fast nearest neighbor classification methods for multispectral imagery. Professional Geographer 44 (2), 191-202.

Harken, J., Sugumaran, R., 2005. Classification of Iowa wetlands using an airborne hyperspectral image: a comparison of the spectral angle mapper classifier and an object-oriented approach. Canadian Journal of Remote Sensing 31 (2), 167-174.

Hay, G.J., Blaschke, T., Marceau, D.J., Bouchard, A., 2003. A comparison of three imageobject methods for the multiscale analysis of landscape structure. ISPRS Journal of Photogrammetry \& Remote Sensing 57, 327-345.

Hay, G.J., Castilla, G., Wulder, M.A., Ruiz, J.R., 2005. An automated object-based approach for the multiscale image segmentation of forest scenes. International Journal of Applied Earth Observation and Geoinformation 7, 339-359.

Heiden, U., Segl, K., Roessner, S., Kaufmann, H., 2007. Determination of robust spectral features for identification of urban surface materials in hyperspectral remote sensing data. Remote Sensing of Environment 111 (4), 537-552.

http://www.drone-pixy.com/. Access date, 20/07/2008.

Janeau, J.L., Bricquet, J.P., Planchon, O., Valentin, C., 2003. Soil crusting and infiltration on very steep slopes in northern Thailand. European Journal of Soil Science 5, 543-553.

Jetten, V., Boiffin, J., De Roo, A., 1996. Defining monitoring strategies for runoff and erosion studies in agricultural catchments: a simulation approach. European Journal of Soil Science 47, 579-592.

Jia, G.J., Burke, I.C., Goetz, A.F.H., Kaufmann, M.R., Kindel, B.C., 2006. Assessing spatial patterns of forest fuel using AVIRIS data. Remote Sensing of Environment 102, 318-327.

Kraus, K., Waldhäusl, P., 1998. Manuel de photogrammétrie: principes et procédés fondamentaux. Hermès, Paris, $407 \mathrm{pp}$.

Laliberte, A.S., Rango, A., Havstad, K., Paris, J., Beck, R., Mcneely, R., Slaughter, A., 2004 Object-oriented image analysis for mapping shrub encroachment from 1937 to 2003 in southern New Mexico. Remote Sensing of Environment 93 (1-2), 198-210.

Lambin, E.F., 1999. Monitoring forest degradation in tropical regions by remote sensing: some methodological issues. Global Ecology and Biogeography 8, 191-198.

Le Bissonnais, Y., Fox, D., Bresson, L.M., 1998. Incorporating crusting processes in erosion models. In: Boardman, J., Favis-Mortlock, D. (Eds.), Modelling Soil Erosion by Water. Springer-Verlag, Berlin, pp. 237-246.

Lee, K.S., Lee, G.B., Tyler, E.J., 1988. Determination of soil characteristics from Thematic Mapper data of a cropped organic-inorganic soil landscape. Soil Science Society of America Journal 52, 1100-1104.

Leonard, J., Andrieux, P., 1998. Infiltration characteristics of soils in Mediterranean vineyards in southern France. Catena 32, 209-223.

Lindeberg, T., 1994. Scale-Space Theory in Computer Vision. Kluwer Academic Publishers, Dordrecht, Netherlands, 407 pp.

Matinfar, H.R., Sarmadian, F., Alavi Panah, S.K., Heck, R.J., 2007. Comparisons of objectoriented and pixel-based classification of land use/land cover types based on Landsat7, ETM+ spectral bands (case study: arid region of Iran). American-Eurasian Journal of Agricultural \& Environmental Sciences 2 (4), 448-456.

Metternicht, G.I., Fermont, A., 1998. Estimating erosion surface features by linear mixture modeling. Remote Sensing of Environment 64 (3), 254-265.

Mori, M., Hirose, Y., Akamatsu, Y., Li, Y., 2004. Object based classification of IKONOS data for rural land use mapping. In ISPRS (Ed.), XXth ISPRS Congress, Geo-Imagery Bridging Continents, Istanbul, Turkey, Commission III papers, Vol. XXXV, part B3.

Moussa, R., Voltz, M., Andrieux, P., 2002. Effects of the spatial organization of agricultural management on the hydrological behaviour of a farmed catchment during flood events. Hydrological Processes 16, 393-412.

Platt, R.V., Rapoza, L., 2008. An evaluation of an object-oriented paradigm for land use land cover classification. Professional Geographer 60, 87-100.
Phua, M.H., Tsuyuki, S., Lee, J.S., Sasakawa, H., 2007. Detection of burned peat swamp forest in a heterogeneous tropical landscape: a case study of the Klias Peninsula, Sabah, Malaysia. Landscape and Urban Planning 82 (3), 103-116.

Poesen, J., Lavee, H., 1994. Rock fragments in top soils: significance and processes. Catena 23, 1-28.

Richter, R., Schlaepfer, D., 2002. Geo-atmospheric processing of airborne imaging spectrometry data. Part 2: atmospheric/topographic correction. International Journal of Remote Sensing 23, 2631-2649.

Robinson, D.A., Phillips, C.P., 2001. Crust development in relation to vegetation and agricultural practice on erosion susceptible, dispersive clay soils from central and southern Italy. Soil and Tillage Research 60, 1-9.

Shoshany, M., 1992. A simulation of bidirectional reflectance distributions of various surface microstructures. International Journal of Remote Sensing 13 (12), 2355-2361.

Shoshany, M., 2000. Detection and analysis of soil erodibility patterns using ai photographs of the Avisur Highlands, Israel. The Hydrology-Geomorphology Interface: Rainfall, Floods, Sedimentation, Land Use (Proceedings of the Jerusalem Conference, May 1999). IAHS-AISH Publication, vol. 261, pp. 127-139.

Snelder, D., Bryan, R.B., 1995. The use of rainfall simulation tests to assess the influence of vegetation density on soil loss on degraded rangeland in the Baringo District, Kenya. Catena 25, 105-116.

Solberg, R., Egeland, T., 1993. Automatic feature selection in hyperspectral satellite imagery. IEEE Proceedings of the International Geoscience and Remote Sensing Symposium: Tokyo, Japan, pp. 472-474.

Thomas, N., Hendrix, C., Congalton, R.G., 2003. A comparison of urban mapping methods using high-resolution digital imagery. Photogrammetric Engineering and Remote Sensing 69 (9), 963-972.

Van Coillie, F.M.B., Verbeke, L.P.C., De Wulf, R.R., 2007. Feature selection by genetic algorithms in object-based classification of IKONOS imagery for forest mapping in Flanders, Belgium. Remote Sensing of Environment 110 (4), 476-487.

Wang, J., Hsu, A., Shi, J.C., O'Neil, P., Engman, T., 1997. Estimating surface soil moisture from SIR-C measurements over the Little Washita River watershed. Remote Sensing of Environment 59, 308-320.

Wassenaar T., 2001. Soil surface feature detection in the French vine-cultivated Mediterranean region by remote sensing at very high spatial resolution. $\mathrm{PhD}$ dissertation, Montpellier Graduate School of Agronomy, $228 \mathrm{pp}$.

Wassenaar, T, Andrieux, P. Baret, F, Robbez-Masson, JM 2005. Soil surface infiltration capacity classification based on the bi-directional reflectance distribution function sampled by aerial photographs. The case of vineyards in a Mediterranean area. Catena 62, 94-110.

Weber, B., Olehowski, C., Knerr, T., Hill, J., Deutschewitz, K., Wessels, D.C.J., Eitel, B. Büdel, B., 2008. A new approach for mapping of Biological Soil Crusts in semi desert areas with hyperspectral imagery. Remote Sensing of Environment 112, 2187-2201

Wiegand, C.L. Everitt, J.H. Richardson, A.J., 1992. Comparison of multispectral video and SPOT/HRV observations for cotton affected by soil salinity. International Journal of Remote Sensing 13 (8), 1511-1525.

Willhauck, G., 2000. Comparison of object-oriented classification techniques and standard image analysis for the use of change detection between SPOT multispectral satellite images and aerial photos. International Archives of Photogrammetry and Remote Sensing Part B 3, 214-221.

Yu, Q, Gong P. Clinton, N., Biging, G., Kelly, M., Schirokauer, D., 2006, Object-based detailed vegetation classification with airborne high spatial resolution remote sensing imagery. Photogrammetric Engineering and Remote Sensing 72 (7) 799-811. 